\title{
Effect of Ferric Sodium EDTA administration, in combination with vitamin C, folic acid, copper gluconate, zinc gluconate and selenomethionine, on cardiovascular risk evaluation: exploration of the HRV frequency domain
}

\begin{abstract}
Background: Anaemia is a frequent co-morbidity in old patients affected by chronic heart failure and/or respiratory diseases. Using the Heart Rate Variability (HRV) analysis is possible to provide an evaluation of the safety and the effectiveness of intervention.

Objective: To evaluate the efficacy and safety of Ferric Sodium EDTA in combination with vitamin C, folic acid, copper gluconate, zinc gluconate and selenomethionine (Ferachel forte ${ }^{\circledR}$ ) 2 tabs/day for 24 days in elderly patients with secondary anaemia, by exploring the HRV frequency domain.

Methods: In 45 elderly patients with secondary anaemia and/or low-moderate kidney failure, laboratory values after administration of Ferric Sodium EDTA, 2 tabs a day, in combination with vitamin C, folic acid, copper gluconate, zinc gluconate and selenomethionine (Ferachel forte ${ }^{\oplus}$ ) for 24 days ( $\mathrm{N}=16$ patients) or ferrous gluconate $63 \mathrm{mg} /$ day added to saline solution, administered using intravenous access during the hospitalization period of $15 \pm 5$ days ( $N=29$ patients) were evaluated. Also, ECG signals and bioelectrical impedance (BIA) were measured.

Results: Oral iron supplementation with Ferric Sodium EDTA, in combination with vitamin C, folic acid, copper gluconate, zinc gluconate and selenomethionine (Ferachel forte ${ }^{\circledast}$ ) confirmed to be effective and safe about the cardiovascular risk in old patients. This study showed the real superiority of the oral administration about the cardiovascular risk in elderly patients in comparison with intravenous administration of ferrous gluconate.

Conclusion:This study confirms that Ferric Sodium EDTA combination (Ferachel forte ${ }^{\oplus}$ ) can be a valid alternative to ferrous gluconate intravenous therapy (gold standard) in the treatment of secondary anaemia in elderly patients. In fact, during the treatment, efficacy results have been maintained without statistically significant variations about cardiovascular risk, evaluated by exploring the HRV frequency domain.
\end{abstract}

Keywords: Anaemia, cardiovascular risk, ferric sodium EDTA, spectral analysis, HRV frequency domain, elderly, kidney failure

\section{Introduction}

All causes of anaemia give a reduction of haemoglobin level and red blood cells value and haematological problems have a high impact on the quality of life. Anaemia is defined as a condition in which the body has a decreased number of circulating erythrocytes, or Red Blood Cells (RBCs), that become insufficient to meet the body's physiologic needs.
Consequently, anaemia can also be defined as a decreased hemoglobin concentration or RBC mass compared with age-matched controls. The World Health Organization (WHO) defines anaemia as a Haemoglobin $(\mathrm{Hb})$ less than $13 \mathrm{~g} /$ $\mathrm{dL}$ in adult men and less than $12 \mathrm{~g} / \mathrm{dL}$ in nonpregnant adult women [1].

Iron deficiency (ID) and Iron-Deficiency Anaemia (IDA) are globally recognized, in daily
Nicola Marchitto ${ }^{1 *}$, Alessia Petrucci², Liuba Fusco ${ }^{3}$, Annalisa Curcio 4 , Adriana Romano ${ }^{4}$, Michele Pironti ${ }^{4}$ and Gianfranco Raimondi ${ }^{5}$

${ }^{1}$ Alfredo Fiorini Hospital, Terracina, (Latina), Italy 
clinical practice, as frequent medical conditions. ID is defined as a level's reduction of total body iron, especially iron stores, with preservation of levels of erythroid iron. IDA is a more severe condition in which low levels of iron are associated with anaemia and the presence of microcytic hypochromic red cells [2].

Anaemia is a common, multi-factorial, relatively mild condition in elderly, with $\mathrm{Hb}$ levels near $10-11 \mathrm{~g} / \mathrm{dL}$ in most subjects. However, it can be associated with a variety of adverse outcomes, including longer hospitalization, disability, and increased mortality risk [3].

Regarding $\mathrm{Hb}$ threshold to be used to define anaemia in elderly individuals, discussions have been reported, since WHO criteria were based on statistical distributions in reference samples that did not include individuals $>65$ years of age. Several studies reported that a $\mathrm{Hb}$ value $<12 \mathrm{~g} / \mathrm{dL}$ is commonly considered indicative of anaemia in elderly of both sexes, since $\mathrm{Hb}$ values in apparently healthy elderly individuals are generally lower than those in younger adults and the differences between males and females tend to disappear with aging $[3,4]$.

In old patients, the main causes of anaemia are Iron Deficiency Anaemia (IDA) and anaemia of chronic diseases (or functional ID), that can be affected by several factors, including malnutrition, delay gastric emptying and occult blood loss [5].

In elderly, Chronic Gastrointestinal (GI) diseases represent the most frequent causes of ID and IDA, leading to both iron loss and malabsorption. Chronic upper and lower GI blood losses can be related to a variety of pathologies like esophagitis, gastritis, peptic ulcer, Inflammatory Bowel Disease (IBD), neoplastic disease, and ano-rectal lesions, such as haemorrhoids. Furtherly, GI bleeding is increased in multimorbidity patients, taking concomitantly chronic medications, like NonSteroidal Anti-Inflammatory Drugs (NSAIDs) and/or antithrombotic therapies [3,5].

Malnutrition can be associated with inadequate dietary iron intake and absorption and can be worsen by decline of biological and cognitive functions, i.e. a reduction of appetite and of taste sensation. Also, depressive syndromes, particularly frequent in older populations, are recognized to be associated with a worsening of nutritional state. Furthermore, in depressive disorders occurs dysregulation of the neuroendocrine and sympathetic nervous systems, potentially affecting erythropoiesis $[3,5,6]$.

Iron malabsorption is also relatively frequent in the elderly and can be affected by Helicobacter pylori (HP) infection, autoimmune atrophic gastritis, celiac disease, IBD, and long-term use of Proton Pump Inhibitors (PPI) [3,5].

Several studies evaluated anaemia frequency in older adults, showing a range from $8 \%$ to $25 \%$, with increased percentage in subjects older than 85 years old. In this population, anaemia can influence mortality and cognitive/ physical performance, increasing number of falls and hospitalizations. Therefore, the evaluation of iron blood level and the relative treatment or follow-up is crucial $[3,5]$.

Recent studies underline that iron administration is associated with improvements of cardiovascular outcomes and quality of life $[2,7,8]$.

Using the Heart Rate Variability (HRV) analysis of the spectral components in the frequency domain is possible to explore the neurovegetative system. Numerous physiological conditions and diseases have an impact factor on the dimension of the area of each peak of frequency range on the HRV power spectrum. Some studies have used spectral HRV and blood pressure variability analysis in a large group of patients and it has been observed that the increase in total HRV and LF power is associated with survival, while the progressive decreases of HRV have been associated with deterioration and death. Alterations of the spectral analysis are correlated with the severity of the disease, the use of this method for the assessment of the state of cardiac and non-cardiac diseases, could provide an evaluation of the prognosis and determine the effectiveness of intervention $[9,10]$.

\section{- Aim of the study}

The aim of this study is to confirm the efficacy and safety of Ferric Sodium EDTA in combination with vitamin $\mathrm{C}$, folic acid, copper gluconate, zinc gluconate and selenomethionine (Ferachel forte $) 2$ tabs a day for a treatment period of 24 days, in elderly patients with secondary anaemia, about cardiovascular risk and quality of life, explored by HRV frequency domain evaluation.
${ }^{2}$ Sapienza University of Rome, Italy ${ }^{3}$ Cardiology Department, Villa Laura, Bologna, Italy ${ }^{4}$ Merqurio Pharma, Naples, Italy ${ }^{5}$ Department of Medical-Surgical Sciences and Biotechnologies, Sapienza University of Rome, Italy

*Author for correspondence: n.marchitto@ausl.latina.it 


\section{Methods}

45 elderly patients (age 79,4 $\pm 10,1$ years old) with a recent diagnosis of secondary anaemia due to iron deficiency and/or low-moderate kidney failure were enrolled. The patients were divided into 2 groups: 16 patients were treated with oral administration of Ferric Sodium EDTA 2 tabs a day, corresponding to $60 \mathrm{mg}$ of iron, in combination with vitamin $\mathrm{C}$, folic acid, copper gluconate, zinc gluconate and selenomethionine (Ferachel forte) for 24 days; 29 patients were treated with ferrous gluconate $63 \mathrm{mg} / \mathrm{day}$ added to saline solution administered using intravenous access during the hospitalization period of $15 \pm 5$ days. The enrolled patients had low-moderate kidney failure (mean creatinine value: $1,1 \pm 0,6 \mathrm{mg} / \mathrm{dL}$ in the group with oral administration of Ferric Sodium EDTA combination and $1,4 \pm 1 \mathrm{mg} / \mathrm{dlL}$ in the group with intravenous administration of ferrous gluconate). Improvement of laboratory values, such as haemoglobin and sidereamia level, and electrocardiographic trace with a length of 2-5 minutes before and after the administration of Ferric Sodium EDTA combination or ferrous gluconate, were evaluated.

Also, the ECG signal and the Bioelectrical Impedance (BIA) were measured. For the ECG signal analysis, Cardio CE palm version 2.0 (XAI-Medica) was used to register standard ECG and beat to beat ECG for Heart Rate variability evaluation. The Bioelectrical Impedance Analysis (BIA) has been analyzed with the Bodygram PRO 3,0 (Akern).

Using a short registration of the electrocardiographic trace the T-peak to T-end index $(\mathrm{Tp} / \mathrm{Te})$ and the $\mathrm{Qt}$ correct interval $(\mathrm{QTc})$ have been measured [11].

Using a short registration of the electrocardiograph with a length of $2-5 \mathrm{~min}$, the spectral analysis reveals three main peaks, describable as the VLF (very low frequency) that includes very low frequencies with values between 0 and $0.04 \mathrm{~Hz}$ that are influenced by the regulation of the temperature and from the humoral systems, the LF (low frequency) that includes low frequencies between 0.04$0.15 \mathrm{~Hz}$, that are associated both to the sympathetic modulation and to the sympathovagal modulation depending on the baroceptive control index of activation of the sympathetic system, the HF (high frequency) which includes the frequencies between $0.15-0.4 \mathrm{~Hz}$, that are associated with parasympathetic activation index, and reflect the vagal modulation of the sinus rhythm associated with the respiratory arrhythmia and finally the Total Power which is the sum of the three peaks or the sum of the single spectral powers $(\mathrm{VLF}+\mathrm{LF}+\mathrm{HF})[9,10]$.

Statistical analysis is performed using Paired T-test with Sigmastat v. 3.5 analysis program. Differences were considered significant when $\mathrm{P}<0,05$.

\section{Results}

Data collected in this study confirm that oral treatment with Ferric Sodium EDTA, in combination with vitamin $\mathrm{C}$, folic acid, copper gluconate, zinc gluconate and selenomethionine (Ferachel forte) at the dosage of $60 \mathrm{mg}$ (2 tabs a day) is an efficacy and safety treatment as preliminary referred. Both results in hemoglobin $(\mathrm{Hb})$ and sideraemia levels showed that treatment with oral iron supplementation for 24 days is as effective as intravenous iron infusion, administrated during hospitalization period (15 \pm 5 days). In particular, $\mathrm{Hb}$ levels raised from $9.5 \pm 1.3 \mathrm{~g} / \mathrm{dL}$ to $11.7 \pm 1.9 \mathrm{~g} / \mathrm{dL}(\mathrm{p}=0.001)$ in the group treated with Ferric Sodium EDTA (TABLE 1). The corresponding increase in $\mathrm{Hb}$ levels in intravenous iron-treated group was from $8.9 \pm 1.5 \mathrm{~g} / \mathrm{dL}$ to $9.9 \pm 1.9 \mathrm{~g} / \mathrm{dL}(\mathrm{p}=0.001$; TABLE 2). Similar results were obtained for sideraemia levels: from $19.5 \pm 5.6 \mathrm{mcg} / \mathrm{dL}$ to $53.8 \pm 25.9 \mathrm{mcg} / \mathrm{dL}(\mathrm{p}=0.001$; TABLE 1$)$ for oral iron administration group; and from $19.6 \pm$ $12.2 \mathrm{mcg} / \mathrm{dL}$ to $37.1 \pm 21.9 \mathrm{mcg} / \mathrm{dL}(\mathrm{p}=0.001$; TABLE 2) for intravenous therapy group.

\section{- Safety results}

Treatment with Ferric Sodium EDTA in combination with vitamin $\mathrm{C}$, folic acid, copper gluconate, zinc gluconate and selenomethionine (Ferachel forte ${ }^{\circ}$ ) did not modify ECG parameters, without bringing concerns about high liquid amounts administered to such a sensitive patient population, such is the elderly patient with low-moderate kidney failure (TABLE 1).

Data showed that intravenous iron supplementation exposes patients to a greater water supply due to iron dilution into saline solution. Intravenous iron supplementation gave a statistically significant variation of the T-peak to T-end value that represents a predictive 


\begin{tabular}{|c|c|c|c|}
\hline & Control & Effect & p-Value \\
\hline $\mathrm{Hb}(\mathrm{g} / \mathrm{dL})$ & $9.5 \pm 1.3$ & $11.7 \pm 1.9$ & 0.001 \\
\hline $\mathrm{Fe}^{++}(\mathrm{mcg} / \mathrm{dL})$ & $19.5 \pm 5.6$ & $53.8 \pm 25.9$ & 0.001 \\
\hline RR (msec) & $778.5 \pm 179.1$ & $814.5 \pm 172.9$ & 0.125 \\
\hline LF (msec) & $600.5 \pm 626.1$ & $1442.4 \pm 3017.3$ & 0.625 \\
\hline $\mathrm{HF}(\mathrm{msec})$ & $854.9 \pm 909.9$ & $2780.1 \pm 6137.1$ & 0.688 \\
\hline Tp-e (msec) & $96.8 \pm 14.9$ & $95.8 \pm 12.9$ & 0.844 \\
\hline QTc (msec) & $317.3 \pm 28.6$ & $318.3 \pm 30.6$ & 0.625 \\
\hline Tp-e/QTc & $0.304 \pm 0.04$ & $0.301 \pm 0.04$ & 0.844 \\
\hline Resistance $(\Omega)$ & n.a. & n.a. & n.a. \\
\hline Reactance $(\Omega)$ & n.a. & n.a. & n.a. \\
\hline
\end{tabular}

TABLE 2. Intravenous ferrous gluconate $63 \mathrm{mg} / \mathrm{day}$ into saline solution $500 \mathrm{~mL}$, administered during the hospitalisation period (15 \pm 5 days).

\begin{tabular}{|c|c|c|c|}
\hline & Control & Effect & p-Value \\
\hline $\mathrm{Hb}(\mathrm{g} / \mathrm{dL})$ & $8.9 \pm 1.5$ & $9.9 \pm 1.9$ & 0.001 \\
\hline $\mathrm{Fe}^{++}(\mathrm{mcg} / \mathrm{dL})$ & $19.6 \pm 12.2$ & $37.1 \pm 21.9$ & 0.001 \\
\hline $\mathrm{RR}(\mathrm{msec})$ & $755.0 \pm 243.4$ & $779.0 \pm 234.4$ & 1.000 \\
\hline $\mathrm{LF}(\mathrm{msec})$ & $1684.1 \pm 2622.1$ & $2016.5 \pm 3191.1$ & 0.818 \\
\hline $\mathrm{HF}(\mathrm{msec})$ & $4601.1 \pm 6561.2$ & $3312.0 \pm 4369.3$ & 0.378 \\
\hline $\mathrm{Tp}-\mathrm{e}(\mathrm{msec})$ & $91.8 \pm 16.2$ & $99.1 \pm 11.6$ & 0.048 \\
\hline $\mathrm{QTc}(\mathrm{msec})$ & $340.0 \pm 42.8$ & $352.7 \pm 62.2$ & 0.105 \\
\hline $\mathrm{Tp}-\mathrm{e} / \mathrm{QTc}$ & $0.271 \pm 0.04$ & $0.282 \pm 0.04$ & 0.562 \\
\hline Resistance $(\Omega)$ & $517.6 \pm 139.6$ & $503.6 \pm 172.9$ & 0.018 \\
\hline Reactance $(\Omega)$ & $41.5 \pm 19.5$ & $38.5 \pm 18.3$ & 0.160 \\
\hline
\end{tabular}

parameter of arrhythmic risk (FIGURE 1). This trend is confirmed by the evaluation of the difference in the electrical resistance measured using a bioimpedenziometric test (FIGURE 2).

More interesting data are noted analyzing electrocardiographic results regarding HRV frequency domain after the treatment with Ferric Sodium EDTA combination at the dosage of 60 mg/day for 24 days (TABLE 3 and FIGURE 3), because this positive trend is confirmed by the absence of statistically significant reduction ( $\mathrm{p}=0.097$ ) of the vagal tone using the Fast Fourier Transformation analysis or FFT-HF (TABLE 3) and the relative statistically significant reduction $(\mathrm{p}=0.049)$ of the vagal tone using the Autoregressive Analysis or AR-HF (TABLE 3 and FIGURE 3). In the patients enrolled in this study, the oral administration confirms the safety of the treatment at high dosage (2 tabs a day).

\section{Discussion}

The therapy with Ferric Sodium EDTA, in combination with vitamin $\mathrm{C}$, folic acid, copper gluconate, zinc gluconate and selenomethionine (Ferachel forte ${ }^{\circ}$ ) is a new iron formulation used for oral treatment of patients with secondary anaemia. Ferric Sodium EDTA is a novel iron source that already reported large efficacy and safety data in several setting, such as anaemic pregnant women [12-14], anaemic pre-school and school-aged children and adolescents [1519].

In addition, several meta-analyses concluded that Ferric Sodium EDTA, already as single component, is highly effective in controlling iron deficiency and reducing the prevalence of iron-deficiency anaemia in men, women, and children [20-22]. Furtherly, Ferric Sodium EDTA is recommended for the mass fortification of high-phytate cereal flours and for sauces with a high peptide content (e.g. fish sauce, soy sauce), by the WHO Guidelines on food fortification with micronutrients.

The use of Ferric Sodium EDTA in combination with vitamin $\mathrm{C}$, folic acid, copper gluconate, zinc gluconate and selenomethionine (Ferachel forte) was evaluated in elderly patients with secondary anaemia due to iron deficiency and/or low-moderate kidney failure, since this population is often exposed to adverse events related to intravenous iron therapy. These events can be related to injection site, such as phlebitis 
FIGURE 1. Descriptive Analisys of the Tpeak to Tend index in the group treated with intravenous ferrous gluconate therapy $63 \mathrm{mg} /$ day (in saline solution $500 \mathrm{~mL}$ ).

FIGURE 2. Descriptive Analysis of the Bioelectrical Impedence Analysis (BIA) in the group treated with intravenous ferrous gluconate therapy $63 \mathrm{mg} /$ day (in saline solution $500 \mathrm{~mL}$ ).

\section{Tpeak to $T$ end index}

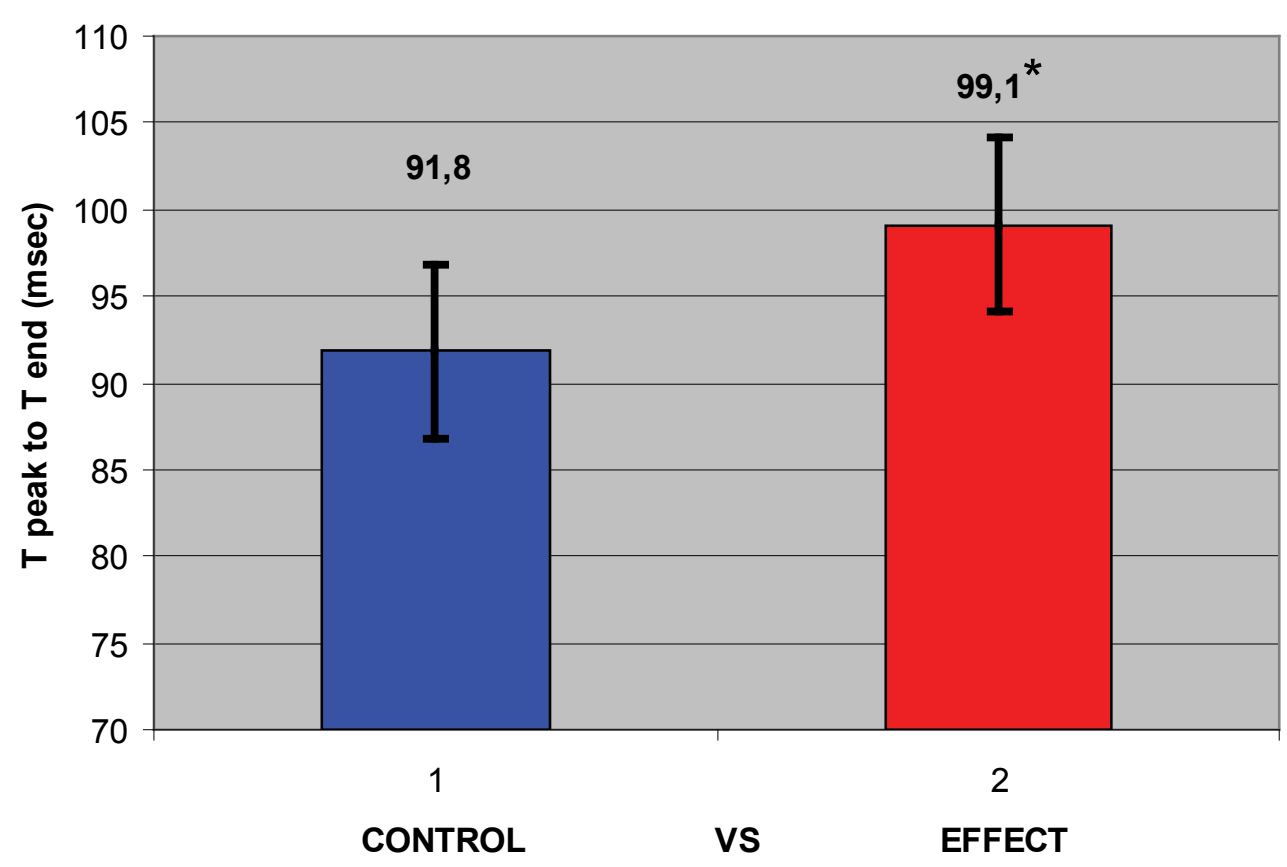

RESISTANCE

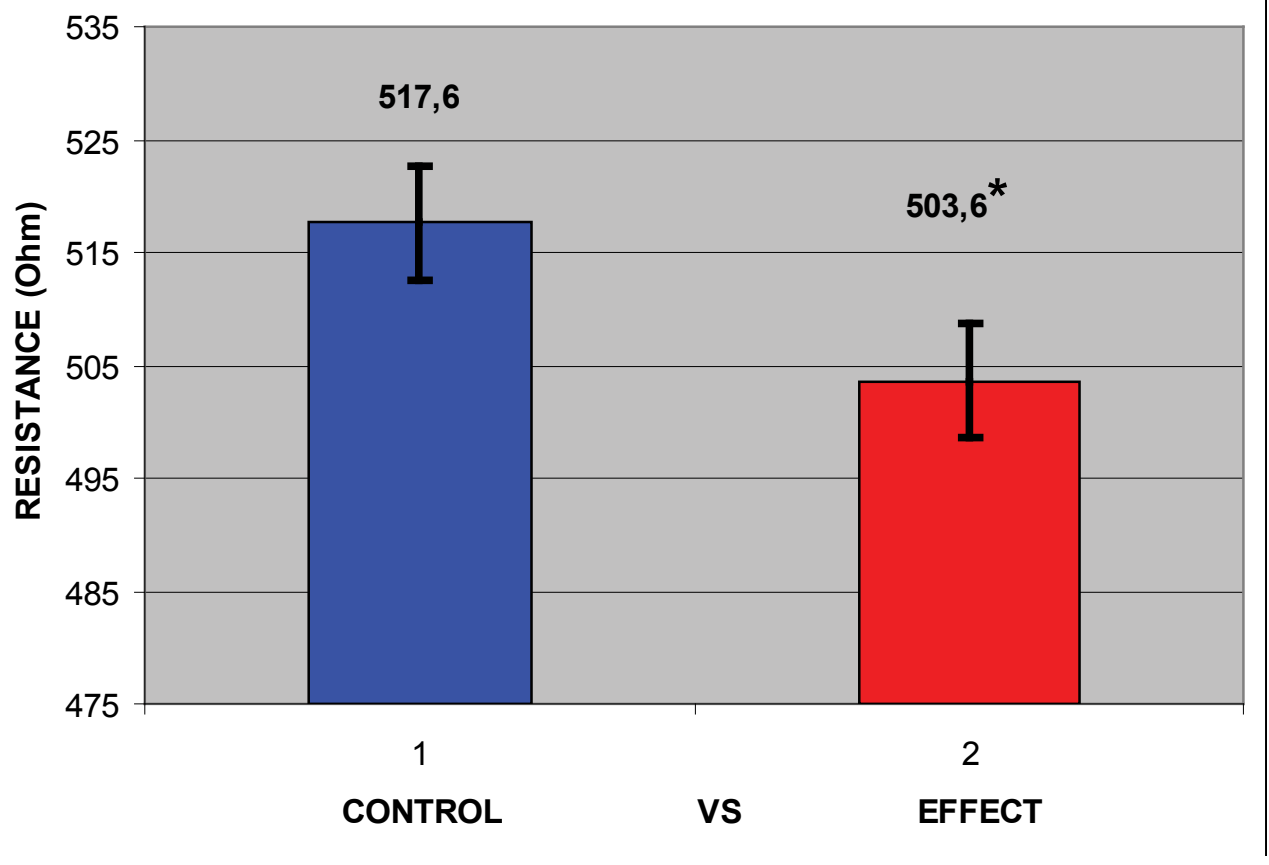

and thrombophlebitis, and/or can increase the risk of allergic reactions and/or aggravate preexisting conditions such as heart failure or renal failure.

The results showed treatment efficacy (TABLE 1) and safety (TABLE 3) of the oral iron formulation. In particular, data pointed out the real superiority of the oral administration about the cardiovascular risk analysed exploring the HRV frequency domain in old patients in comparison with the intravenous administration of ferrous gluconate (FIGURE 3). 


\section{HRV High Frequencies (Regressive Analisys)}

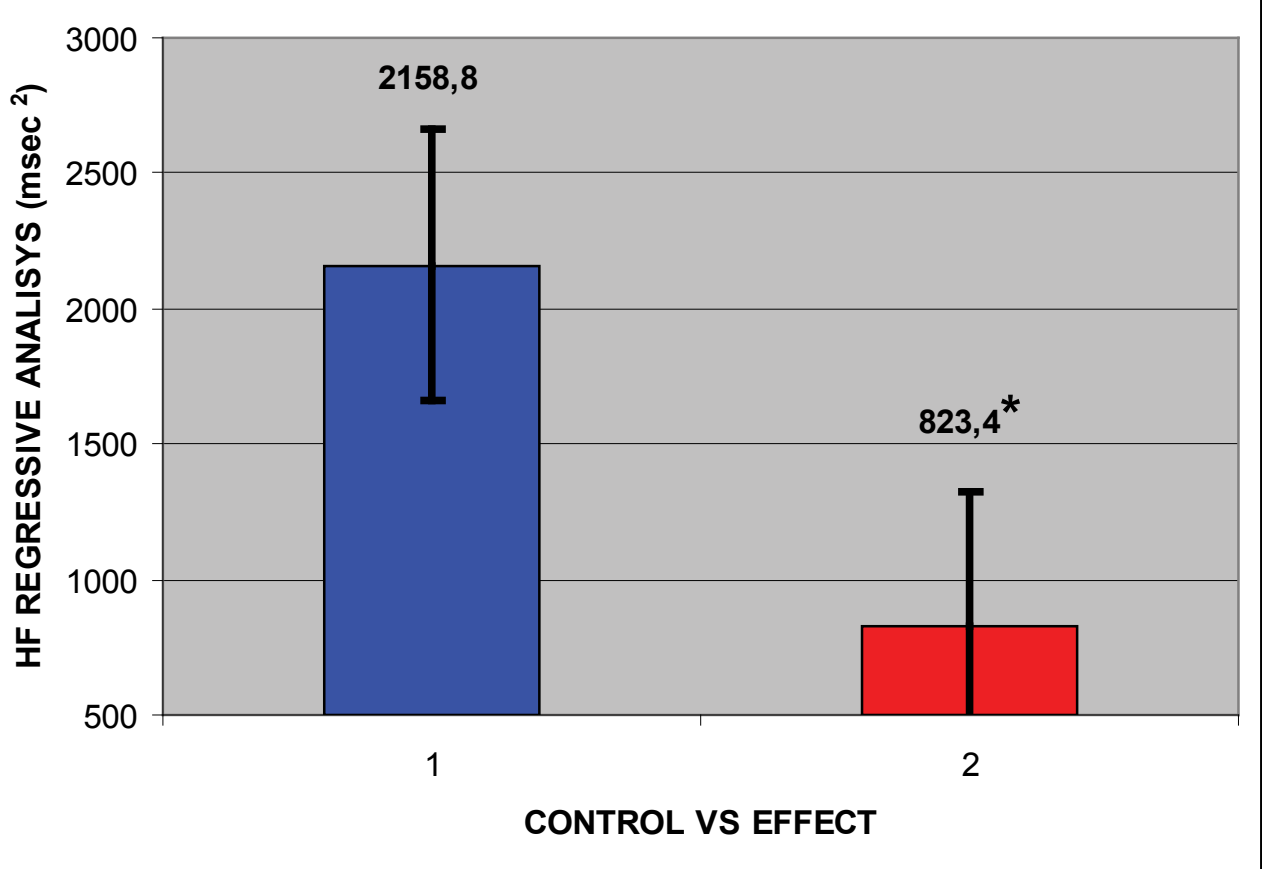

FIGURE 3. Descriptive Analysis of the HRV High Frequencies $(p=0.049)$ explored by Regressive Analysis in the group treated with Ferric Sodium EDTA in combination with vitamin $\mathrm{C}$, folic acid, copper gluconate, zinc gluconate and selenomethionine

(Ferachel forte $^{\circledR}$ ) 2 tabs/ day for 24 days.

\begin{tabular}{|c|c|c|c|}
\hline & Control & Effect & $p<0.050$ \\
\hline fft-LF & $2254.5 \pm 3471.6$ & $858.0 \pm 1140.1$ & 0.145 \\
\hline $\mathrm{fft}-\mathrm{HF}$ & $2704.8 \pm 3982.5$ & $883.8 \pm 964.9$ & 0.097 \\
\hline fft-TOTAL & $8447.1 \pm 1746.9$ & $2290.4 \pm 2404.5$ & 0.188 \\
\hline $\mathrm{fft}-\mathrm{LF} / \mathrm{HF}$ & $0.813 \pm 0.589$ & $1.062 \pm 0.930$ & 0.335 \\
\hline AR-LF & $1817.8 \pm 2629.3$ & $1024.3 \pm 1419.1$ & 0.313 \\
\hline AR-HF & $2158.8 \pm 2622.4$ & $823.4 \pm 810.6$ & $0.049^{*}$ \\
\hline AR-TOTAL & $6398.6 \pm 1012.8$ & $1012.8 \pm 3345.5$ & 0.193 \\
\hline AR-LF/HF & $0.811 \pm 0.659$ & $0.858 \pm 0.762$ & 0.806 \\
\hline
\end{tabular}

These preliminary results are comfortable but not applicable to a broad spectrum of patients with secondary anaemia.

\section{Conclusion}

This study confirms that Ferric Sodium EDTA in combination with vitamin $\mathrm{C}$, folic acid, copper gluconate, zinc gluconate and selenomethionine (Ferachel forte') is a valid and safe alternative to ferrous gluconate intravenous therapy (gold standard) in the treatment of secondary anaemia in elderly patients, because during the treatment efficacy results has been maintained without statistically significant variations about cardiovascular risk, evaluated exploring the HRV frequency domain.

\section{Conflict of Interest}

The authors declare that they have no conflict of interest.

\section{Informed consent}

Informed consent was obtained from all individual participants included in the study.

\section{Acknowledgment}

The Authors are particularly grateful to Petrucci Alessia for English translation and Marchitto Lino, Maisano Carla Maria and Marchitto Federica for organizational aspects. 


\section{References}

http://www.who.int/vmnis/indicators/ haemoglobin.pdf

Longo DL, Camaschella C. Irondeficiency anemia. N. Engl. J. Med. 372(19), 1832-1843 (2015).

Busti F, Campostrini N, Martinelli $\mathrm{N}$, et al. Iron deficiency in the elderly population, revisited in the hepcidinera. Front. Pharmacol. 5(1), 83 (2014).

Goodnough LT, Schrier SL. Evaluation and management of anaemia in the elderly. Am. J. Hematol. 89(1), 88-96 (2014).

De-Franceschi L, Iolascon A, Taher $A$, et al. Clinical management of iron deficiency anaemia in adults: Systemic review on advances in diagnosis and treatment. Eur. J. Intern. Med. 42, 16-23 (2017).

Stewart R, Hirani V. Relationship between depressive symptoms, anaemia, and iron status in older residents from a national survey population. Psychosom. Med. 74(2), 208-213 (2012).

Anker SD, Kirwan BA, van Veldhuisen DJ, et al. Effects of ferric carboxymaltose on hospitalisations and mortality rates in iron-deficient heart failure patients: an individual patient data meta-analysis. Eur. J. Heart Fail. 20(1), 125-133 (2018).

Herter-Aeberli I, Eliancy K, Rathon $\mathrm{Y}$, et al. In Haitian women and preschool children, iron absorption from wheat flour-based meals fortified with sodium iron EDTA is higher than that from meals fortified with ferrous fumarate, and is not affected by Helicobacter pylori infection in children. Br. J. Nutr. 118(4), 273-279 (2017).
Rovere L, Teresa M, Robert A, et al. Baroreflex sensitivity and heart-rate variability in prediction of total cardiac mortality after myocardial infarction. The Lancet. 351(9101), 478-484 (1998).

Shaffer F, Ginsberg JP. An overview of heart rate variability metrics and norms. Front. Pub. Health. 5, 258 (2017).

Tse G, Gong M, Wong WT, et al. The $\mathrm{T}_{\text {peak }}-\mathrm{T}_{\text {end }}$ interval as an electrocardiographic risk marker of arrhythmic and mortality outcomes: A systematic review and meta-analysis. Heart. Rhythm. 14(8), 1131-1137 (2017).

Han XX, Sun YY, Ma AG, et al. Moderate NaFeEDTA and ferrous sulfate supplementation can improve both hematologic status and oxidative stress in anaemic pregnant women. Asia. Pac. J. Clin Nutr. 20(4), 514-520 (2011).

Van TP, Berger J, Nakanishi Y, et al. The use of NaFeEDTA-fortified fish sauce is an effective tool for controlling iron deficiency in women of childbearing age in rural Vietnam. J. Nutr. 135(4), 2596601 (2005).

Cignini P, Mangiafico L, Padula F, et al. Supplementation with a dietary multicomponent (Lafergin ( $\left.{ }^{\circledast}\right)$ ) based on Ferric Sodium EDTA (Ferrazone $\left({ }^{\oplus}\right)$ ): Results of an observational study. $J$. Prenat. Med. 9, 1-7 (2015).

Huo J, Sun J, Miao H, et al. Therapeutic effects of NaFeEDTA-fortified soy sauce in anaemic children in China. Asia. Pacific. J. Clin. Nutr. 11(2), 123-127 (2002).

Muthayya S, Thankachan P, Hirve S, et al. Iron fortification of whole wheat flour reduces iron deficiency and iron deficiency anemia and increases body iron stores in Indian school-aged children. J. Nutr. 142(11), 1997-2003 (2012).

Longfils P, Monchy D, Weinheimer H, et al. A comparative intervention trial on fish sauce fortified with NaFe-EDTA and $\mathrm{FeSO}_{4}+$ citrate in iron deficiency anaemic school children in Kampot, Cambodia. Asia. Pac. J. Clin. Nutr. 17(2), 250-257 (2008).

Teshome EM, Otienoc W, Terweld SR, et al. Comparison of home fortification with two iron formulations among Kenyan children: Rationale and design of a placebo-controlled non-inferiority trial. Contemp. Clin. Trials. Comm. 7, 1-10 (2017).

Huo JS, Yin JY, Sun J, et al. Effect of $\mathrm{NaFe}$ EDTA-fortified soy sauce on anaemia prevalence in China: A systematic review and meta-analysis of randomized controlled trials. Biomed. Environ. Sci. 28(11), 788-798 (2015).

De-Regil LM, Jefferds MED, PeñaRosas JP. Point-of-use fortification of foods with micronutrient powders containing iron in children of preschool and schoolage. Cochrane. Database. Syst. Rev. 23, 11 (2017).

Wang B, Zhan S, Xia Y, et al. Effect of sodium iron ethylenediaminetetra-acetate (NaFeEDTA) on haemoglobin and serum ferritin in iron-deficient populations: a systematic review and meta-analysis of randomised and quasi-randomised controlled trials. Br. J Nutr. 100(6), 11691178 (2008).

World Health Organization. Guidelines on food fortification with micronutrients/edited by Lindsay Allen, Bruno de Benoist, Omar Dary and Richard Hurrell. 